\title{
PENGUKURAN EFETIFITAS PENJADWALAN PRODUKSI \\ PADA PERUSAHAAN JOB ORDER
}

\author{
Khafizh Rosyidi
}

Dosen Teknik Industri Fakultas Teknik Universitas Yudharta Pasuruan

\begin{abstract}
ABSTRAK
Production Planing and Control (PPC) merupakan faktor utama dalam setiap perusahaan untuk menunjang kelancaran proses produksi, baik perusahaan mass production maupun perusahaan job order. Perencanaan produksi memiliki peranan yang sangat penting dalam mengantisipasi supaya tidak terjadi keterlambatan dalam pemenuhan target produksi. Oleha karena itu harus dibuat perencanaan produksi (production planning) secara baik. Di lingkungan CV. YAD tingkat produksi harian didasarkan pada permintaan total harian untuk setiap model produk yang akan diproduksi selama satu minggu dibagi dengan banyaknya hari kerja dalam minggu tersebut. Rasio untuk setiap produk menentukan banyaknya unit yang harus diproduksi setiap hari dalam satu minggu agar dapat memenuhi sasaran dalam master schedule planning (MPS). Sebagaimana hasil penelitian bahwa permintaan total mingguan untuk produk A, B dan C di CV. YAD berturut-turut adalah: 500 unit, 2000 unit, dan 5000 unit. Dalam satu minggu diasumsikan terdapat 6 hari kerja, sehingga tingkat produksi harian untuk produk $\mathrm{A}=500 / 6=83,33$ unit (dibulatkan menjadi 84 unit), $\mathrm{B}=2000 / 6=$ 333,33 unit (dibulatkan menjadi 334 unit), dan $\mathrm{C}=5000 / 6=833,33$ unit (dibulatkan menjadi 834 unit). Berdasarkan pengukuran efektifitas dari metode sequencing, dapat diambil keputusan berkaitan dengan sekuens operasi mana yang terbaik untuk dipilih. Apabila perusahaan lebih memprioritaskan untuk meminimumkan keterlambatan penyerahan produk ke pelanggan, sebaiknya memilih pendekatan FCFS dengan sekuens operasi atau tugas: B-A-C-D, karena memiliki nilai rata-rata keterlambatan terkecil yaitu: 1,75 hari. Tetapi apabila perusahaan ingin memaksimumkan utilisasi sumber daya, disarankan untuk memilih dengan sekuens operasi atau tugas: A-B-C-D, karena memiliki nilai utilisasi tertinggi yaitu 46,3\%. Bagaimanapun juga aturan-aturan yang berkaitan dengan penetapan prioritas kerja dalam operasi manufacturing harus ditetapkan secara rasional, jelas dan konsisten dengan tujuan strategik dari pengambil keputusan perusahaan itu sendiri.
\end{abstract}

Kata kunci: Perencanaan produksi, penjadwalan produksi, Job Order

\section{PENDAHULUAN}

Dewasa ini perkembangan dunia industri semakin maju, hal itu terbukti dengan banyaknya industri-industri baru yang mengelola berbagai macam produk. Dengan demikian kebutuhan akan faktor-faktor produksi menjadi bertambah banyak. Kegiatan perusahaan mempunyai hubungan yang sangat erat dengan kegiatan produksi untuk memenuhi kebutuhan pasar. Dalam penyelenggaraan kegiatan produksi perlu adanya sebuah perencanaan dan pengendalian produksi yang baik. Oleh karena itu di dalam dunia usaha Production Planing and inventory control (PPIC) memiliki peranan yang sangat penting. Supaya tidak sampai terjadi keterlambatan dalam pemenuhan target produksi, maka harus dibuat perencanaan produksi (production planning) secara baik. Perencanaan produksi merupakan faktor utama di dalam perusahaan untuk menunjang kelancaran proses produksi, baik perusahaan besar, tingkat menengah maupun kecil.

Dalam perumusan perencanaan produksi, terdapat perbedaan yang signifikan antara perusahaan yang mass-production dan job order. Berdasar atas pengalaman selama ini, pihak perusahaan belum pernah menerapkan dua (2) layanan prioritas, yaitu First Come First Serve (FCFS) atau dengan 
Random Order (R/O). Prioritas FCFS, yaitu order yang diterima pertama kali oleh Bagian PPW (Perencanaan dan Pengendalian Workshop) akan dieksekusi terlebih dahulu dengan set schedules yang paling awal. Prioritas ini biasanya digunakan pada saat seluruh order yang diterima bersifat internal dan material tersedia di lantai produksi. Sedangkan kriteria acak atau Random Order $(\mathrm{R} / \mathrm{O})$ digunakan pada saat order yang diterima sangat kompleks dan order tersebut terbagi atas internal orders dan external orders.

Eksekusi order pada kriteria FCFS di lapangan juga didasarkan atas tingkat urgensi order dan dipengaruhi oleh ketaktersediaan material pada saat order tersebut diterima. Kriteria R/O digunakan untuk mengantisipasi keterlambatan pengiriman kedua jenis order tanpa memfokuskan pekerjaan pada satu jenis order saja.

Dengan tidak adanya perencanaan produksi dalam hal penjadwalan produksi seringkali menyebabkan lamanya waktu eksekusi order atau shoptime yang terkadang berbeda dengan set jadwal yang diestimasikan sebelumnya. Teknik layanan melalui prioritas penjadwalan yang selama ini diterapkan dinilai tidak cukup baik untuk mengatasi persoalan penjadwalan produksi tersebut, khususnya untuk persoalan tipe jobshop yang cenderung memiliki variabilitas produksi yang tinggi.

Penjadwalan jobshop memiliki karakteristik sebagai penjadwalan job pada mesin dan setiap job memiliki routing (urutan mesin) yang unik [1]. Penjadwalan jobshop diperlukan untuk memaksimumkan efisiensi dan utilitas sumber daya di lantai produksi.
Penjadwalan juga dapat diartikan sebagai penugasan job atau operasi dalam beberapa tahapan tertentu [2]. Sebagaimana yang menjadi tujuan dalam penelitian ini yakni dengan melakukan pengukuran efektivitas penjadwalan produksi jobshop dengan kriteria prioritas produksi agar dapat meminimalisir keterlambatan target produksi.

\section{METODOLOGI PENELITIAN}

Sebelum proses pengolahan data dilakukan, maka sebelumnya dilakukan studi pendahuluan dan observasi langsung terhadap sistem penjadwalan yang ada di perusahaan. Data-data yang diperlukan dalam penelitian ini, adalah: (1) data mesin, (2) data routing dan waktu proses, serta (3) data order.

Tahapan penelitian yang digunakan dalam proses penjadwalan jobshop, yaitu :

1. Menghitung makespan dengan menggunakan pendekatan heuristik Algoritma Giffler Thompson (GT) aturan prioritas SPT.

2. Menghitung makespan dengan menggunakan pendekatan komputasi Modul SPT pada software Quantitative System (QS) version 3.0.

3. Melakukan perbandingan makespan Algoritma GT, makespan dengan bantuan QS modul SPT, serta perolehan makespan aktual (estimasi waktu standar aktual).

4. Melakukan perhitungan efisiensi jadwal dan penghematan waktu 
operasi sebelum dan sesudah

Produksi. Perencanaan produksi penjadwalan dilakukan.

5. Melakukan perbandingan antar menetapkan kerangka kerja untuk penjadwalan produksi induk (Master metode di atas dan menetapkan metode optimal berdasarkan nilai perolehan makespan minimum.

6. Melakukan percobaan dengan menggunakan aturan Random pada QS kemudian dilakukan analisis hasil terhadap perolehan makespan dengan aturan SPT.

\section{HASIL DAN PEMBAHASAN}

Proses produksi dalam suatu perencanaan haruslah konsisten dengan rencana bisnis, dimana dalam sistem Manufacturing Resource Planning (MRP) Production Schedule) dan pelaksanaan manufakturing.

Operasi manufakturing harus dijadwalkan agar item-item diproduksi tepat waktu. Kapan suatu pesanan harus diselesaikan (when it is due)? Pekerjaan apa yang seharusnya diselesaikan atau dijalankan berikut pada work centre tertentu? Itu semua merupakan pertanyaan inti yang berkaitan dengan pengendalian prioritas (priority control).

Diketahui daftar pemesanan produk $\mathrm{CV}$. YAD pada minggu pertengahan bulan Desember 2015 adalah sebagai berikut :

merupakan input bagi proses Perencanaan

Tabel 1. : Data 4 order CV. YAD

\begin{tabular}{|c|c|c|c|c|}
\hline $\begin{array}{c}\text { Order } \\
\text { (Inisial produk) }\end{array}$ & Waktu pesan & Waktu jadi & $\sum$ & WDR \\
\hline A & 15 Desember 2015 & 21 Desember 2015 & 500 & 5 \\
B & 15 Desember 2015 & 19 Desember 2015 & 2000 & 3 \\
C & 15 Desember 2015 & 19 Desember 2015 & 5000 & 3 \\
D & 17 Desember 2015 & 02 Januari 2015 & 800 & 8 \\
\hline
\end{tabular}

Dalam hal ini terdapat beberapa metode yang dapat digunakan untuk menetapkan prioritas dalam operasi manufakturing, antara lain:

Critical ration, dihitung melalui pembagian waktu yang tersisa (banyaknya jam atau hari kerja di antara sekarang dan due date) dengan

$$
C R=\frac{\text { Time remaining }(T R)}{\text { Work Days Remaining }(W R)}=\frac{\text { Due Date }- \text { Today's Date }}{\text { Work (Lead) Time Remaining }}
$$

kerja yang tersisa (total setup, run, wait, move, and queue times).

Berdasarkan informasi pada tabel, kita dapat menghitung Critical Ratio (CR),menggunakan formula berikut : 
(Due date - Now) / Work Days Reaming

$$
\begin{aligned}
& =(21 \text { Desember } 2015-15 \text { Desember 2015) } / 5 \\
& =7 \text { days } T R / 5 \text { days } W R \\
& =1,4
\end{aligned}
$$

Order B critical ratio :

(Due date - Now) / Work Days Reaming

$$
\begin{aligned}
& =(19 \text { Desember } 2015-15 \text { Desember } 2015) / 3 \\
& =5 \text { days } T R / 3 \text { days } W R \\
& =1,67 .
\end{aligned}
$$

Order C critical ratio :

(Due date - Now) / Work Days Reaming

$$
\begin{aligned}
& =(19 \text { Desember } 2015-15 \text { Desember 2015) } / 3 \\
& =5 \text { days } T R / 3 \text { days } W R \\
& =1,67 .
\end{aligned}
$$

Order D critical ratio :

(Due date - Now) / Work Days Reaming

$$
\begin{aligned}
& =(2 \text { Januari } 2016-17 \text { Desember 2015 }) / 8 \\
& =16 \text { days } T R / 8 \text { days } W R \\
& =
\end{aligned}
$$

Berdasarkan analisis critical ratio di atas, adalah dirioritaskan untuk dikerjakan terlebih pesanan-pesanan dengan nilai $\mathrm{CR}$ terkecil dahulu.

Tabel 2. Analisis Critical Ratio Dari Empat Tugas di CV. YAD

\begin{tabular}{|c|c|c|}
\hline $\begin{array}{c}\text { Order } \\
\text { (Inisial produk) }\end{array}$ & Critical Ratio (CR) & Urutas Prioritas \\
\hline A & $(21-15) / 5=1,4$ & 1 \\
B & $(19-15) / 3=1,67$ & 2 \\
C & $(19-15) / 3=1,67$ & 3 \\
D & $(2 \mathrm{p}-17 \mathrm{j}) / 8=2$ & 4 \\
\hline
\end{tabular}

Shortest Processing Time (SPT): pesananpesanan dengan jumlah setup and run time yang dibutuhkan pada current work centre terkecil adalah yang diprioritaskan untuk dikerjakan lebih dahulu. Dengan kata lain, pesanan-pesanan yang memiliki waktu pemrosesan terpendek (last amount of setup and run times) memiliki prioritas lebih tinggi untuk dikerjakan terlebih dahulu ada current work centre. Aturan ini dapat menunda pekerjaan-pekerjaan yang mempunyai waktu proses panjang, sehingga direkomendasi untuk digunakan secara sementara saja, dan bukan merupakan aturan yang tetap dalam menentukan prioritas. 
Tabel 3. Penerapan Metode SPT pada CV. YAD

\begin{tabular}{|c|c|c|c|c|}
\hline $\begin{array}{c}\text { Job } \\
\text { (order) }\end{array}$ & $\begin{array}{c}\text { Job work } \\
\text { (processing) } \\
\text { Time (Days) } \\
\text { (1) }\end{array}$ & $\begin{array}{c}\text { Job Due Date } \\
\text { (Days) }\end{array}$ & $\begin{array}{c}\text { Flow Time } \\
\text { (Komulatif dari } \\
\text { processing time) }\end{array}$ & Job Lateness \\
\hline A & 3 & $(3)$ & $(4)$ & $(5)=(4)-(3)$ \\
B & 4 & 5 & 7 & 0 \\
C & 5 & 5 & 12 & 2 \\
D & 7 & 16 & 19 & 7 \\
\hline Total & 19 & - & 41 & 9 \\
\hline
\end{tabular}

$$
\begin{aligned}
& \text { Average Completion Time }=\frac{\text { Sum of Total Flow Time }}{\text { Number of Jobs }}=41 / 4=10,25 \text { days } \\
& \text { Utilization }= \\
& \begin{array}{l}
\text { Total Job Work Time } \\
\text { Sum of Total Flow Time }
\end{array}=19 / 41=0,463 \text { days } \\
& =46,3 \%
\end{aligned}
$$

$$
\begin{aligned}
& \begin{array}{l}
\text { Average Number of Job in } \\
\text { the System }
\end{array}=\frac{\text { Sum of Total Flow Time }}{\text { Total Job Work Time }}=41 / 19=2,16 \text { Jobs } \\
& \text { Average Job Lateness } \\
& \text { Total Late Days } \\
& = \\
& \overline{\text { Number of Jobs }}=9 / 4=2,25 \text { days }
\end{aligned}
$$

Hasil pengukuran efektifitas dari digunakan hanya apabila waktu kerja yang

metode SPT akan dibahas kemudian bersama dengan metode lain.

First come, First served (FCFS). Tugas yang pertama datang ke pusat kerja diproses dahulu. Metode ini seyogyanya tersisa untuk competing orders relatif sama. FCFS akan cocok untuk untuk flow processes karena memiliki work remaining times yang serupa. 
Tabel 4. Penerapan Metode FCFS

\begin{tabular}{|c|c|c|c|c|}
\hline $\begin{array}{c}\text { Job } \\
\text { (order) }\end{array}$ & $\begin{array}{c}\text { Job work } \\
\text { (processing) } \\
\text { Time (Days) } \\
\text { (1) }\end{array}$ & $\begin{array}{c}\text { Job Due Date } \\
\text { (Days) }\end{array}$ & $\begin{array}{c}\text { Flow Time } \\
\text { (Komulatif dari } \\
\text { processing time) }\end{array}$ & Job Lateness \\
\hline A & 3 & $(3)$ & $(4)$ & $(5)=(4)-(3)$ \\
B & 4 & 5 & 7 & 0 \\
C & 3 & 5 & 10 & 2 \\
D & 5 & 16 & 15 & 5 \\
\hline Total & 15 & - & 35 & 7 \\
\hline
\end{tabular}

$$
\begin{aligned}
& \text { Average Completion Time }=\frac{\text { Sum of Total Flow Time }}{\text { Number of Jobs }}=35 / 4=8,75 \text { days } \\
& \text { Utilization }= \\
& \text { Total Job Work Time } \\
& \begin{aligned}
\text { Sum of Total Flow Time } & =15 / 35= \\
& =42,9 \%
\end{aligned}
\end{aligned}
$$
$\begin{aligned} & \text { Average Number of Job in } \\ & \text { the System }\end{aligned}=\frac{\text { Sum of Total Flow Time }}{\text { Total Job Work Time }}=35 / 15=2,33$ Jobs Total Late Days

Average Job Lateness

\begin{tabular}{|c|c|c|c|c|}
\hline $\begin{array}{c}J o b \\
\text { (order) } \\
\text { (1) }\end{array}$ & $\begin{array}{c}\text { Job work } \\
\text { (processing) } \\
\text { Time (Days) } \\
\text { (2) }\end{array}$ & $\begin{array}{c}\text { Job Due Date } \\
\text { (Days) } \\
\text { (3) }\end{array}$ & $\begin{array}{c}\text { Flow Time } \\
\text { (Komulatif dari } \\
\text { processing } \\
\text { time) } \\
\text { (4) }\end{array}$ & Job Lateness \\
\hline A & 3 & 5 & 3 & 0 \\
\hline B & 4 & 7 & 7 & 0 \\
\hline $\mathrm{C}$ & 3 & 16 & 10 & 0 \\
\hline D & 5 & 5 & 15 & 10 \\
\hline Total & 15 & - & 35 & 10 \\
\hline
\end{tabular}

$$
=\overline{\text { Number of Jobs }}=7 / 4=1,75 \text { days }
$$

Earliest due date (EDD). Tugas-tugas yang mempunyai earliest due date yang dipilih pertama.

Tabel 5. Penerapan Earliest Due Date (EDD) 


$$
\begin{aligned}
& \text { Average Completion Time }=\frac{\begin{array}{l}
\text { Sum of Total Flow Time } \\
\text { Number of Jobs }
\end{array}}{\text { Utilization }=}=35 / 4=8,75 \text { days } \\
& \begin{array}{l}
\text { Total Job Work Time } \\
\text { Sum of Total Flow Time }
\end{array}=15 / 35=0,429 \text { days } \\
& =42,9 \%
\end{aligned}
$$

\begin{tabular}{|c|c|c|c|c|}
\hline $\begin{array}{c}J o b \\
\text { (order) } \\
\text { (1) }\end{array}$ & $\begin{array}{c}\text { Job work } \\
\text { (processing) } \\
\text { Time (Days) } \\
\text { (2) }\end{array}$ & $\begin{array}{c}\text { Job Due Date } \\
\text { (Days) } \\
\text { (3) }\end{array}$ & $\begin{array}{c}\text { Flow Time } \\
\text { (Komulatif dari } \\
\text { processing } \\
\text { time) } \\
\text { (4) }\end{array}$ & Job Lateness \\
\hline $\mathrm{A}$ & 5 & 5 & 5 & 0 \\
\hline B & 3 & 16 & 8 & 0 \\
\hline $\mathrm{C}$ & 4 & 7 & 12 & 5 \\
\hline $\mathrm{D}$ & 3 & 5 & 15 & 10 \\
\hline Total & 15 & - & 40 & 15 \\
\hline
\end{tabular}

$$
\begin{aligned}
& \begin{array}{l}
\text { Average Number of Job in } \\
\text { the System }
\end{array}=\frac{\text { Sum of Total Flow Time }}{\text { Total Job Work Time }}=35 / 15=2,33 \text { Jobs } \\
& \text { Total Late Days } \\
& \text { Average Job Lateness } \\
& = \\
& \overline{\text { Number of Jobs }}=10 / 4=2,5 \text { days }
\end{aligned}
$$

Longest rocessing time (LRT). Tugas-tugas yang mempunyai waktu proses terpanjang yang dipilih terlebih dahulu.

Tabel 6. Penerpan Longest Rocessing Time (LRT)

$$
\begin{aligned}
& \text { Average Completion Time Sum of Total Flow Time } \\
& =\text { Number of Jobs } \\
& \text { Utilization }=\frac{\text { Total Job Work Time }}{\text { Sum of Total Flow Time }}=15 / 40=0,375 \text { days } \\
& =37,5 \%
\end{aligned}
$$

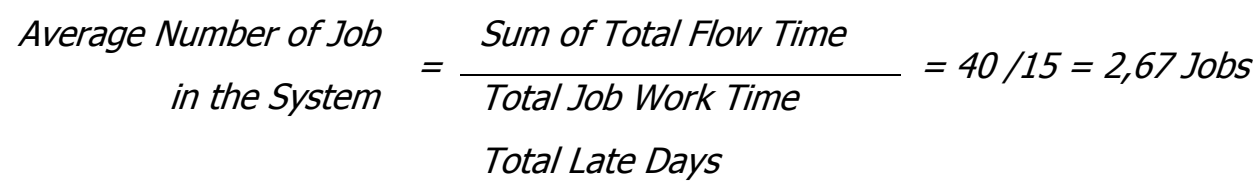

$$
\begin{aligned}
& \text { Average Job Lateness }=\frac{}{\text { Number of Jobs }}=15 / 4=3,75 \text { days }
\end{aligned}
$$


Hasil-hasil pengukuran efektifitas dari keempat metode di atas, apabila ditampilkan bersama maka akan tampak seperti dalam tabel di bawah ini.

Tabel 7. Penguuran Efetifitas dari Empat Metode Sequencing

\begin{tabular}{|c|c|c|c|c|}
\hline \multirow{3}{*}{ Metode } & $\begin{array}{c}\text { Average } \\
\text { Completion } \\
\text { Time (Days) }\end{array}$ & $\begin{array}{c}\text { Avilization } \\
\text { (Days) }\end{array}$ & $\begin{array}{c}\text { Average } \\
\text { Number of Job } \\
\text { in the System } \\
\text { (Jobs) }\end{array}$ & $\begin{array}{c}\text { Average Job } \\
\text { Lateness } \\
\text { (Days) }\end{array}$ \\
\hline SPT & 10,25 & 46,3 & 2,16 & 2,25 \\
FCFS & 8,75 & 42,9 & 2,33 & 1,75 \\
EDD & 8,75 & 42,9 & 2,33 & 2,5 \\
LRT & 10 & 37,5 & 2,67 & 3,75 \\
\hline
\end{tabular}

Berdasarkan ukuran efektifitas dari metode sequencing dalam tabel di atas, kita dapat membuat keputusan berkaitan dengan sekuens operasi mana yang terbaik untuk dipilih. Apabila CV. YAD lebih memprioritaskan untuk meminimumkan keterlambatan penyerahan produk ke pelanggan, sebaiknya berdasarkan kasus di atas memilih metode FCFS dengan sekuens operasi atau tugas: B-A-C-D, karena memiliki nilai rata-rata keterlambatan terkecil yaitu: 1,75 hari. Tetapi apabila CV. YAD ingin memaksimumkan utilisasi sumber daya, dalam kasus di atas disarankan untuk memilih dengan sekuens operasi atau tugas: A-B-C-D, karena memiliki nilai utilisasi tertinggi yaitu: 46,3\%, dengan rata-rata keterlambatan adalah 1,75 hari.

Bagaimanapun juga aturan-aturan yang berkaitan dengan penetapan prioritas kerja dalam operasi manufakturing harus ditetapkan secara rasional, jelas dan konsisten dengan tujuan strategik dari CV. YAD itu sendiri.

\section{Sekuens Produk (Pruduct Sequence)}

Apabila perusahaan (dalam hal ini adalah CV. YAD) ingin merubah sistem penjadwalan berbasis bulanan atau mingguan menjadi berbasis harian, maka perusahaan dapat mengadopsi konsep Just in Time, di mana penjadwalan produksi dilakukan dengan basis harian yang merata. Selanjutnya apabila jenis produk yang akan diproduksi setiap hari itu lebih dari satu jenis, maka dalam hal ini membutuhkan mixed models scheduling. Metode mixed models scheduling merupakan suatu prosedur yang dapat digunakan untuk menentukan minimum banyaknya unit yang diurutkan dalam suatu production run untuk jadwal produksi harian. Metode ini didasarkan pada upaya untuk meminimumkan lot size dan menetapkan ukuran dari production run. Pendekatan untuk melakukan mixed models scheduling didasarkan pada langah berikut.

Menentukan jadwal produksi harian untuk beberapa model dan jenis produk. Tingkat produksi harian didasarkan pada permintaan total harian untu setiap model produk yang akan diproduksi selama satu 
minggu dibagi dengan banyaknya hari kerja dalam minggu itu. Rasio untuk setiap produk menentukan banyaknya unit yang harus diproduksi setiap hari selama minggu itu agar memenuhi sasaran master schedule planning (MPS) untuk minggu itu.

Dalam tabel di bawah ini diasumsikan bahwa permintaan total mingguan untuk produk A, B dan C, berturut-turut adalah: 500 unit, 2000 unit, dan 5000 unit. Dalam satu minggu diasumsikan terdapat 6 hari kerja, sehingga tingkat produksi harian untuk produk $\mathrm{A}=500 / 6=83,33$ unit (dibulatkan menjadi 84 unit), $B=2000 / 6=333,33$ unit (dibulatkan menjadi 334 unit), dan $C=5000 / 6=833,33$ unit (dibulatkan menjadi 834 unit).

Tabel 8. Jadwal Produksi Harian Merata dengan 60 Lot Kecil

\begin{tabular}{|c|c|c|c|c|c|c|c|c|}
\hline \multirow[t]{2}{*}{ Produk } & \multicolumn{5}{|c|}{$\begin{array}{l}\text { Hari produksi dalam } \\
\text { minggu ke } 3 \text { bulan } \\
\text { Desember } 2016\end{array}$} & \multirow[t]{2}{*}{ Total } & \multirow[t]{2}{*}{$\begin{array}{c}\text { Banyak } \\
\text { lot }\end{array}$} & \multirow[t]{2}{*}{$\begin{array}{c}\text { Ukuran } \\
\text { lot }\end{array}$} \\
\hline & 1 & 2 & 3 & & 6 & & & \\
\hline $\bar{A}$ & & & & & & 500 & 6 & 84 \\
\hline B & & & & & & 2000 & 6 & 334 \\
\hline $\mathrm{C}$ & & & & & & 5000 & 6 & 834 \\
\hline
\end{tabular}

\section{PENUTUP}

Berdasarkan penelitian yang dilakukan maka diperoleh kesimpulan bahwa apabila CV. YAD lebih memprioritaskan untuk meminimumkan keterlambatan penyerahan produk ke pelanggan, sebaiknya berdasarkan kasus di atas memilih metode FCFS dengan sekuens operasi atau tugas: B-A-C-D, karena memiliki nilai rata-rata keterlambatan terkecil yaitu: 1,75 hari. Tetapi apabila CV. YAD ingin memaksimumkan utilisasi sumber daya, dalam kasus di atas disarankan untuk memilih dengan sekuens operasi atau tugas: A-B-C-D, karena memiliki nilai utilisasi tertinggi yaitu: 46,3 \%, dengan rata-rata keterlambatan adalah 1,75 hari.

\section{DAFTAR PUSTAKA}

Baker, Kenneth R. 1974. Introduction to Sequencing and Schedulling. John Wiley \& Sons: USA.

Narasimhan, Seetharama L.et al. 1994. Production Planning \& Inventory Control. Prentice-Hall, International Inc : New Jersey: USA. 
Bedworth, David D. et al. 1986. Integrated Production Control Systems. John Wiley \& Sons.

Chase, Richard B. et al. 1990. Production \& Operations :Management A Life Cycle Approach. Toppan Co Ltd: Japan.

Dinata, Andhika. 2008. "Penjadwalan Job Shop dengan Algoritma Penjadwalan Aktif (Studi Kasus di CV. Seruni Furniture Padang)". Laporan Kerja Praktek. Jurusan Teknik Industri: Universitas Andalas, Padang.

Gultom, Robin Parulian. 2006. "Penjadwalan n Job m Mesin Cetak secara Paralel untuk Meminimalkan Waktu Keterlambatan Pencetakan Pada CV. Surya Mas Palembang". Kompilasi Jurnal Skripsi TI-STT Musi Palembang (Oktober 2005) (www.http//:musi.ac.id), diakses 13 Juli 2008.

Laboratorium Sistem Produksi ITB. 2003. Penjadwalan Produksi. Institut Teknologi Bandung : Bandung (www.lspitb.org), diakses 27 Januari 2008.

Meredith, Jack R. et al. 1984. The Management of Operation : 2nd Edition. John Wiley \& Sons, Inc: Canada.

Morton,Thomas E. et al. 1993. Heuristic Schedulling Systems: with applications to production systems\&project management. Jhon Wiley\&Sons, Inc, Canada : USA.
Nasution, Arman Hakim. 2006. Manajemen Industri. PT. Andi Yogyakarta. Yogyakarta.

Nasution, Arman Hakim2. 1999. Perencanaan dan Pengendalian Produksi. PT. Guna Widya. Jakarta.

Panggabean, Henry Pantas. 2002. Jurnal: "Penjadwalan Job Shop Statik dengan Algoritma Simulated Annealing”. Universitas Katolik Parahyangan : Bandung (http://home.unpar.ac.id/), diakses 13 Juli 2008.

Pinedo, Michael L. 2005. Planning and Schedulling in Manufacturing and Services. Springer: USA.

Russel \& Taylor. 2000. Operation Management. Prentice Hall Inc.

Singgih Prasetyo, Soeparno. "Penjadwalan Job Shop untuk Meminimasi Makespan (Studi Kasus di PT Fuji Dharma Electric)". Prosiding Seminar Nasional Manajemen Teknologi II: ITS) 
